

\title{
Field-Based Geoscience Education during the COVID-19 Pandemic: Planning, Execution, Outcomes, and Forecasts
}

\begin{abstract}
Jonathan R. Rotzien, Basin Dynamics LLC and University of Houston, Dept. of Earth and Planetary Sciences, 1875 Post Oak Park Drive, Houston, Texas 77027, USA, jon@basindynamics.com; Ryan Sincavage, Radford University, Geology Dept., Box 6939, Radford, Virginia 24142-6939, USA, rsincavage@radford.edu; Christopher Pellowski, South Dakota School of Mines and Technology, Dept. of Geology and Geological Engineering, 501 E. St. Joseph Street, Rapid City, South Dakota 57701, USA, christopher.pellowski@sdsmt.edu; Yann Gavillot, Montana Tech University, Montana Bureau of Mines and Geology, Butte, Montana 59701, USA, ygavillot@mtech.edu; Harry Filkorn, Pierce College, Physics and Planetary Sciences, 6201 Winnetka Ave., Woodland Hills, California 91371, USA, filkornh@, piercecollege.edu; Scott Cooper, FractureStudies LLC, 99 Rainbow Road, Suite 4-5, Edgewood, New Mexico 87015, USA, scott@, fracturestudies.com; Jeremy Shannon, Michigan Tech University, Geological and Mining Engineering and Sciences, 1400 Townsend Drive, Houghton, Michigan 49931, USA, jmshanno@mtu.edu; Umit Vildiz, Foster Sawyer, Nuri Uzunlar, South Dakota School of Mines and Technology, Dept.of Geology and Geological Engineering, 501 E. St. Joseph Street, Rapid City, South Dakota 57701, USA, umit.yildiz@ sdsmt.edu; foster.sawyer@sdsmt.edu; nuri.uzunlar@sdsmt.edu
\end{abstract}

\begin{abstract}
The undergraduate geoscience experience typically culminates in a field-based capstone course that utilizes outcrop mapping, geologic observation, and interpretation across multiple disciplines to provide the graduating geologist with fundamental field-mapping skills. However, due to the COVID-19 pandemic, many of the field-based geoscience programs have been temporarily suspended or shifted to an online format. To address the demand for graduating seniors in the broad field of geoscience, the South Dakota School of Mines and Technology developed an innovative hybrid course consisting of two parts: (i) a 14-day online course on geological field methods, followed by (ii) a 15-day in-person geologic mapping course based out of Rapid City, South Dakota, USA. Analysis of this new hybrid course provides a benchmark on how to develop and execute field-based geoscience education with greater accessibility to field geology through a combination of online and face-to-face teaching. Our hybrid course model was taught during the first summer of the pandemic (28 June to 28 July 2020), and this experience provided the following insights: (i) there are four key stages to leading a field camp over a five-month timeline: development, logistics planning, implementation, and review; (ii) key decision makers and stakeholders in the process include the students, instructors, field-camp logisticians, campus dining and housing facilitators, fieldstation director, department chair, provost,
\end{abstract}

and the Board of Regents; (iii) logistics, transportation, accommodation, and dining services require advanced levels of consideration to adequately address COVID-19-related risk and uncertainty; (iv) online teaching and exercises can address geological field methods, but they cannot adequately assess a student's ability to map geology in the field; (v) field-mapping exercises need to be adjusted to reduce the number of people in one field area and lower their interaction to support socialdistancing guidelines from relevant government and health authorities; and (vi) plans need to be put into place for overall health and safety as well as contingency plans in the event of an outbreak before and during the field camp. We hope that this experience of delivering a geology field camp during the COVID-19 pandemic is useful in providing a benchmark on reasonable field-camp practices, identifying critical successes and unknowns, and guiding field-camp development during pandemics. We also hope this contribution will serve as a useful guide for universities and businesses that intend to engage in face-to-face activities during this time of uncertainty.

\section{INTRODUCTION}

Undergraduate geoscience disciplines set themselves apart from other natural science curricula in that they generally require a multi-week field-based geologic mapping capstone course to graduate. These field camps cover a broad spectrum of topics, including the subfields of sedimentology, stratigraphy, mineralogy, structural geology, and metamorphic and igneous petrology. Some specialized field camps provide more opportunities for students to develop their interests in fields such as volcanology, geophysics (Bank and Rotzien, 2007), structure and thrust-belt tectonics, sedimentary basin analysis and applied petroleum geoscience (Anderson et al., 1999; Rotzien et al., 2020, and references therein), or environmental hazard mitigation. Whichever type of field camp a student chooses to complete, it is intended to be one of the highlights of their undergraduate geoscience learning experience. However, during the COVID-19 pandemic, many field camps were canceled, postponed, or fully converted to an online format. These cancellations and modifications caused demand for face-to-face field camps for graduating seniors to rise. In order to address this demand, the Black Hills Natural Sciences Field Station (BHNSFS) at the South Dakota School of Mines and Technology (SDSMT) developed a hybrid course consisting of two parts: an online geological field methods course followed by a field-based geologic mapping course.

The task of building this hybrid course was not a simple process. Constructing a field camp during the COVID-19 pandemic required attention to key factors, including: (i) pre-camp online field methods exercises; (ii) logistics, such as accommodations, dining, and transportation; and (iii) contingency

GSA Today, v. 31, https://doi.org/10.1130/GSATG483A.1. CC-BY-NC. 
plans in the case of an outbreak before or during the camp. Building this field camp required significant planning, execution, success - and serendipity - in key areas.

While this course was developed in response to the COVID-19 pandemic, its application is not limited to public-health concerns that limit face-to-face instruction. The geoscience field by its nature requires an intimate understanding of the natural world and, as such, often relies on field-based observation and research. Furthermore, most job descriptions for geoscientists in the U.S. as well as abroad specify the need for fieldwork and competency in working in the field (sensu Oliveri and Bohacs, 2005). Unfortunately, the requirements of a field-based capstone undergraduate course can inadvertently restrict access to our science. A multi-week fieldbased geologic mapping course can be problematic for non-traditional students with family and work obligations that prevent them from traveling to a remote field site for an extended time. Furthermore, the cost of some field-based mapping courses is prohibitive for low-income students, thereby potentially limiting the diversification of practitioners within the geosciences (see Chiarella and Vurro, 2020, for an in-depth discussion on this topic). This public-health crisis also presents an opportunity: by developing robust remote learning opportunities to cultivate geologic mapping skills, we provide an accessible and alternative pathway to experience the capstone undergraduate geoscience course.

While this paper describes just one experience, and we do not have access to every available data point at this time (reviews are still being generated for this course), we feel we do have a particularly insightful view of several key concepts for developing and delivering a hybrid course during the COVID-19 pandemic. This paper has three primary aims: (i) to characterize the portions and extent of the planning, execution, and review process for this course; (ii) to issue a qualitative analysis of what worked and what did not work for this course, from the various perspectives of key stakeholders, including students and instructors; and (iii) to provide a method for an ideal set-up for a hybrid online and field course during a pandemic anywhere in the world.

\section{COURSE DEVELOPMENT AND PREPARATION}

Here we present the four key stages in delivering a hybrid course. The following stages took place over a six-month time period from March to August 2020 and include course development, logistics planning, implementation, and review. The planning for the online and field-course phases is outlined in Table 1 and divided broadly into early and late-stage deliverables and considerations.

Preparation for the online course started shortly after most U.S. institutions shut down or were locked down due to the outbreak in mid-March 2020. At this time, universities and colleges canceled face-toface instruction, closed most of their facilities, and sent students home to finish out the school year through online instruction. As the pandemic situation progressed and affected summer travel plans, multiple field courses that the BHNSFS operates internationally were soon canceled; U.S.based courses were postponed and then finally arranged for an online format. However, there still existed a need to deliver a field course for students wishing to complete their field component and finish their undergraduate education requirements during the summer. In April, our team of instructors began planning for the hybrid online and field-course logistics and curriculum.

Because a five-week-long standard field camp was not feasible for health and safety reasons, we decided on a hybrid course with two distinct parts: (i) a 14-day online webinar-based portion followed immediately by (ii) a 15-day face-to-face field-based portion held in Rapid City, South Dakota, USA. This course was approved because it satisfied the requirements set forth by relevant university and government guidance: (i) having a best practices plan in place for travel, accommodations, dining, and fieldwork; (ii) providing a method for departure and travel to field areas; (iii) incorporating best health, safety, and environmental (HS\&E) practices while in the field; and (iv) having a contingency plan in case someone showed symptoms or tested positive for the virus.

Our online geological field methods course is divided into four primary modules: (i) an introduction to field mapping and reading geologic and topographic maps (three days); (ii) sedimentation, stratigraphy, and basin analysis (four days); (iii) structural geology, and fracture analysis, and mapping geologic structures (six days); and (iv) a final project encompassing mapping, sedimentation, geomorphology, and structural analysis (one day). A new skill or topic pertaining to mapping and interpreting surface and subsurface geological areas of interest was introduced each day.

Our 14-day online portion had 45 students from 18 different U.S.-based undergraduate institutions, and our field-based face-to-face portion had 30 students from 14 different institutions. The course was intentionally designed such that students were given assignments that would take anywhere from 6 to 12 hours to complete. In addition to hand-drawn maps, topographic profiles, and cross sections, only our virtual platform (Zoom), Google Earth, R. Allmendinger's Stereonet, and standard word processing software (Microsoft Office) were required to complete the exercises.

\section{IMPLEMENTATION AND RESULTS}

\section{A Typical Online Course Day}

A typical online day consisted of four main parts: (i) an introductory informal discussion about the course or exercise from the previous day; (ii) a lecture covering a new topic of interest; (iii) a description of the new project or exercise of the day to be completed by the students for a grade; and (iv) an afternoon Q\&A session typically in a group forum lasting 1-2 hours to cover any existing questions the students had regarding the exercise.

We covered topics of the day, including pacing, three-point problems, planar measurements (strike and dip of bedding, joints, etc.), trend and plunge measurements, interpreting physical stratigraphy, measuring stratigraphic section, building weathering profiles to trace mappable units and formation boundaries, interpreting depositional environments, measuring fractures and folds, strike/dip and trend/plunge measurements, mapping geological contacts and structures using both field photos and remote sensing data, using geomorphology and outcrop weathering patterns to trace lithofacies and formation boundaries to establish structures, and more. Following the lecture and a short break, the instructor would then present the daily exercise. Overall, most morning lectures and exercise introductions took 2-3 hours to complete.

Following the end of the morning session, each recorded lecture was submitted to the course platform-D2L-an online repository for all materials. Each PowerPoint lecture and slides were also submitted to D2L by the end of each day, along with the project description and grading rubric. It was critical to be able to grade everything using digital copies to return to the students who were 
TABLE 1. SUGGESTED CHECKLIST AND TIMETABLE FOR A SUCCESSFUL HYBRID ONLINE FIELD METHODS AND FIELD COURSE

\begin{tabular}{|c|c|c|c|c|}
\hline & Students & Instructors & Course leadership (director) & Logistics \\
\hline $\begin{array}{l}6 \text { months until } \\
\text { course }\end{array}$ & $\begin{array}{l}\text { Evaluate camps to attend in USA } \\
\text { and internationally, and apply }\end{array}$ & $\begin{array}{l}\text { Define objectives and scope of } \\
\text { class for online and field portions; } \\
\text { seek rules and regulations from } \\
\text { government authorities (travel } \\
\text { bans, virus testing requirements) }\end{array}$ & $\begin{array}{l}\text { Advertise field camp; identify pre- } \\
\text { planning issues and challenges } \\
\text { pertaining to scholastic, ADA, and } \\
\text { logistical needs }\end{array}$ & $\begin{array}{l}\text { Discuss with course leadership } \\
\text { what is required for the camp }\end{array}$ \\
\hline
\end{tabular}

5 months until Register for field camp based on course
Brainstorm projects and generate risk matrix for evaluating projects
4 months until Take any remaining prerequisites
course

3 months until course
Complete pre-camp readings; continue to complete course prerequisites

$\begin{array}{ll}\begin{array}{l}2 \text { months until } \\ \text { course }\end{array} & \begin{array}{l}\text { Students acquire necessary } \\ \text { equipment for course }\end{array} \\ \begin{array}{l}1 \text { month until } \\ \text { course }\end{array} & \begin{array}{l}\text { Pack and final preparations for } \\ \text { course }\end{array} \\ \begin{array}{l}\text { Online course } \\ \text { delivery (Phase I) }\end{array} & \begin{array}{l}\text { Attend course, learn, complete } \\ \text { exercises as part of a team, } \\ \text { receive and implement feedback } \\ \text { on exercises }\end{array}\end{array}$

Field camp delivery (Phase II)
Attend course, learn, complete exercises, receive and implement feedback on exercises
Post-course review Implement new knowledge on geoscience toward graduate school or career; provide written and oral feedback on the course to all stakeholders
Develop projects in line with objectives; identify list of necessary equipment for online and field courses

Test projects and peer-review among the instructors; reevaluate the scope, goals, and deliverables for each project

Test online delivery; scope out field areas for feasibility due to changing environmental and health and safety issues

Finalize project preparation

Deliver course lectures, Q\&A sessions (for credit), exercises; grade exercises; provide feedback to students and other instructors regarding academic and logistical challenges

Using health \& safety guidelines developed for this course, deliver course lectures, $Q \& A$ sessions, exercises; grade exercises; provide feedback to students and other instructors regarding academic and logistical challenges

Meet to discuss merits, limitations, pitfalls and suggestions and critiques for next learning event
Work with all stakeholders and state government to develop health and safety plan; oversee

Iterate scenarios and camp requirements with course leadership; finalize what is development of projects that serve required to run a safe field camp the needs of the student

Compile and finalize equipment and requirements list from all stakeholders (i.e., what do they need to be successful?)

Guide project development; work with all stakeholders to complete tasks

Assess final peer-review of projects

Final coordination with all key stakeholders

Provide evaluations of course content to instructors; continue to work with accommodations, vehicles, dining to prepare for field-camp phase

Observe and evaluate the range Deliver on all items; maintain open and variability in project outcomes communication with instructors to to compare merits, limitations, and see what works and what doesn't provide feedback to instructors and key stakeholders
Reserve vehicles, accommodations, dining programs, based on information from course leadership

Prepare site for field camp; run-through of contingency scenarios identified by leadership and instructors and authorities

Work with instructors and leadership to finalize a contingency scenarios document

Final coordination of all logistical items including travel, vans, dining, accommodations

Final check and amendments due to changing needs and last-minute alterations, if needed other governmental and health
Meet with all stakeholders to discuss merits, limitations, pitfalls, and suggestions and critiques for next learning event
Meet with stakeholders to discuss merits, limitations, pitfalls, and suggestions and critiques for next learning event working in all parts of the country. This online field-methods course required modules from five instructors and the director of the BHNSFS, totaling 80-200 hours of work per instructor to prepare, deliver, and complete grading for the online course exercise. By the end of the 14-day online phase, the students had received 15 GB of data, information, and exercises, constituting thousands of hours of analysis and a huge scientific, technical, and economic value.

\section{Pre-Trip Planning and COVID-19 Infection Scenarios}

In the weeks leading up to the field-based portion of the course, instructors and the director alike consistently reminded the students to use social distancing and quarantine measures and other health and safety guidelines to limit the risk of becoming infected with COVID-19 prior to arrival in Rapid City. Students were encouraged to drive to Rapid City, if possible. Students and instructors who flew to Rapid City Regional Airport were encouraged to wear a face mask in transit to and from the airport, during the flight, and while in the airport. Since there were no widely available testing kits at the time, no tests were administered prior to the field course.

The pre-planning and execution of the logistics and safety included general daily practices for students and instructional staff: (i) students and staff should have a pocket-sized card with the Center for Disease Control (CDC) list of COVID-19 symptoms for reference; (ii) students should be encouraged to practice respiratory etiquette by covering coughs and sneezes and wash their hands or apply hand sanitizer afterward; (iii) members of the camp would maintain social distancing of 6 feet $(2 \mathrm{~m})$ while on campus and in the field areas whenever practical and during meals in the cafeteria or outside; and (iv) separate cohorts should not be around one another or interact at any time throughout the duration of the course. The final part 
was quite difficult during meal times and likely during afterhours.

If at any time a member of the course were to test positive, it was important to have contingency plans. Should one person in the cohort test positive, then the entire cohort would have to go into quarantine and either finish the current field project or begin online instruction modules for the 14-day period as per South Dakota Dept. of Health Guidelines. Should an instructor become infected and thus unable to effectively teach, then the other instructor of the cohort would have to oversee the cohort and implement the online instruction until the infected instructor could begin working again. There should be at least two additional instructors to fill in as replacements should the need arise.

\section{A Typical Field-Course Day}

Many of the field-course days were similar to camps in pre-COVID-19 times, yet due to the shortened and condensed nature of the 15-day field course and increased safety precautions, the schedule and projects necessarily had to change in specific ways. The field phase of the course featured three mapping projects, each in a different location, which allowed students to map and interpret structural domes, igneous intrusive bodies, and metamorphic basement rock assemblages to gain confidence in understanding complex structures and also appreciate the diverse and challenging geologic history of the Black Hills.

Mapping projects were introduced via Zoom the evening prior to the field mapping day. Every field area that was typically mapped in previous years was downsized to a small section of area to map because the number of field days for each project was decreased by $\sim 20 \%-50 \%$ in order to complete three projects in less than 15 days. Project descriptions, assignments, related materials, and base maps were assembled by the instructors into large envelopes, and one was delivered to the door of each student's dormitory room to limit face-to-face contact. Students were divided into three cohorts, each containing 10 students, and two faculty were assigned to each cohort. On mapping days, students had breakfast from 6:30-7:30 a.m. Each of the field vehicles, vans, was loaded with five students and one instructor, who also served as the driver, and departed for the field at 8 a.m. Typical drive times to the field areas were roughly 40-80 minutes, allowing mapping from $\sim 9$ a.m.-4:30 p.m. Students worked in groups of two at each field area and were required to wear face masks when less than 6 feet $(2 \mathrm{~m})$ apart (Fig. 1). At 4:30 p.m., vans departed the field area and returned home for dinner at 6 p.m. Nightly virtual lectures occurred at 7:30 p.m. Logistics pertaining to the specific details of transportation, accommodations, and dining are described in the following sections. All students brought their own laptops except one, and that student was provided a laptop by the university.

When selecting project areas, consideration was given to the additional need for extra parking space given that the field camp was operating with twice as many vans as usual and there had to be enough room to not only accommodate the extra vans, but if two or more cohorts were at the same project area, then there had to be enough room for each cohort to be properly distanced.

Another key difference was that in a traditional field-camp course, there is likely a senior instructor or camp coordinator who would act as the lead instructor to facilitate the outcrop lectures and discussions and/or other faculty who would take turns as lead instructor for different projects based on their areas of expertise. There may even be cases where in the traditional setting, several instructors may come and go over the period of six weeks to lead the various projects. Under the cohort model that we employed, each cohort had two instructors assigned to the 10 students for the entire time, and there were no exchanges or visits by other instructors. The instructors for each cohort had to be comfortable and familiar enough with the geology of each of the project areas to be able to lead the outcrop discussions and not rely on the senior instructor or another instructor for each of the different projects.

\section{Transportation}

Each cohort of 10 students and two faculty was assigned two 12-passenger vans for transportation to the field, to evenly divide the cohort (Fig. 2). Front-to-back passenger seating in the four rows of each vehicle was $2-1-1-2$, and passengers were required to wear face coverings at all times in the vehicle. Prior to entering the vehicle, temperature checks were recorded. Students were required to sit in the same
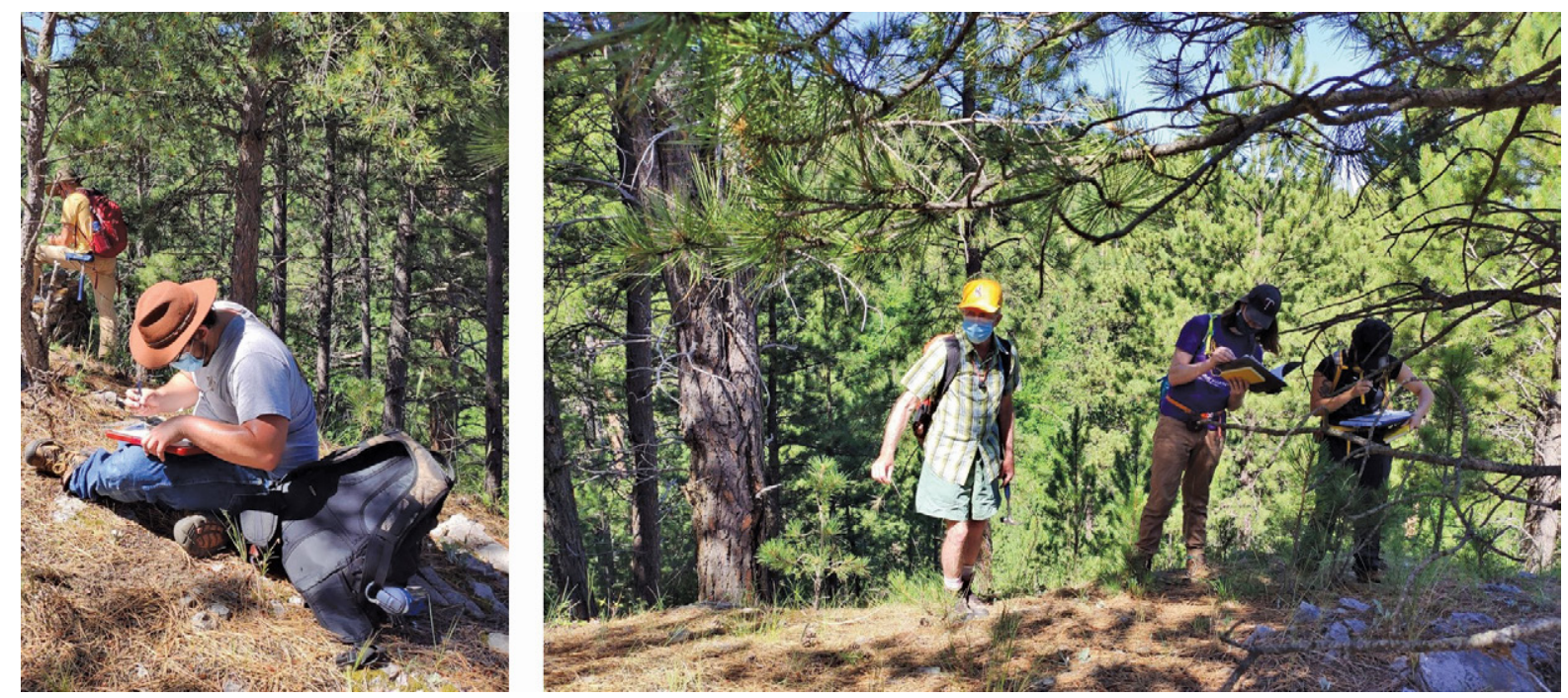

Figure 1. Students and instructors maintain social distancing and wear masks while mapping geologic structures in the Black Hills of South Dakota (July 2020). 

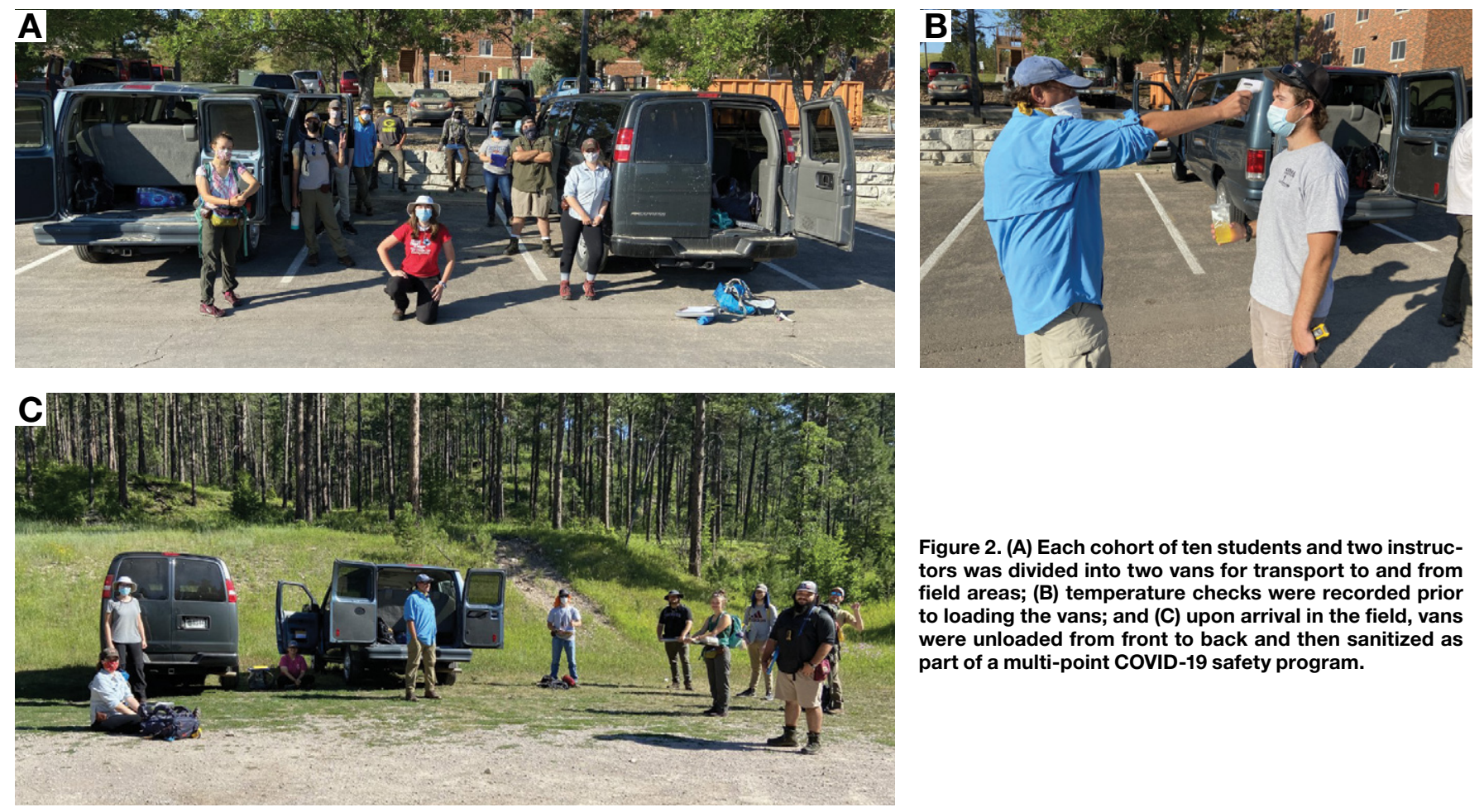

Figure 2. (A) Each cohort of ten students and two instructors was divided into two vans for transport to and from field areas; (B) temperature checks were recorded prior to loading the vans; and (C) upon arrival in the field, vans were unloaded from front to back and then sanitized as part of a multi-point COVID-19 safety program.

seat each day, and vans were loaded from back to front and unloaded from front to back. Upon reaching the field and home destinations, disinfectant spray was used on all handled interior and exterior vehicle surfaces. Furthermore, windows were kept open and air conditioning could be set to high, but not to max because that would recirculate air.

\section{Accommodations}

Field-camp leaders worked closely with SDSMT campus authorities to accommodate students in single-occupancy dorm rooms to mitigate the risk of a potential outbreak. Each 10-student cohort was placed on a separate floor in Connolly Hall residential dormitory. Three instructors and 10 students lived off campus, so only four instructors and 20 students lived on campus for the duration of the field camp. On campus, all members of the field camp were required to socially distance and wear face coverings. While it was impractical to monitor students' after-hours activities, students were encouraged not to go off campus because of the risk of being introduced to COVID-19 at bars and other areas where social gatherings are common.

\section{Dining}

Field-camp leaders worked closely with SDSMT campus authorities to provide safe meals to mitigate the risk of a potential outbreak. Dining took place at Surbeck Center in the main cafeteria. Upon entry and wearing a face mask, members of the field camp were to stay spaced 6-feet $(2 \mathrm{~m})$ apart while a member of the dining team served them their meal. Blue-tape Xs were placed on the floor to remind students to keep the space of social distancing. Self-service was minimal. The dining room tables were spaced far apart and only one person was allowed per table to facilitate social distancing. Furthermore, laminated cards with "clean" and "dirty" sides were used to show which tables had been cleaned and were ready to accommodate a diner, and following a meal, the card was to be flipped over, revealing to the dining team that the table needed to be cleaned prior to accommodating the next diner.

\section{INTERPRETATION AND REVIEW OF THE HYBRID COURSE}

Students, instructors, and key stakeholders of the South Dakota state university system provided important feedback (both anonymous and not) on the merits, limitations, and attributes of this course. First, the introduction to field mapping methods online served three important purposes: (i) to provide distinct exercises, most of them in different sedimentary basins from around the world and each on a different mapping topic that is critical to the development of a well-rounded and successful field geologist; (ii) to introduce digital mapping methods, including the use of freely accessible high-resolution imagery and 3-D visualization such as Google Earth to aid in the field mapping process; and (iii) to teach observational skills and first principles in sedimentary basin analysis (i.e., what are the lithofacies, and how are different sedimentary structures throughout turbidite beds used to determine paleocurrent direction, or what are the types of fractures, faults, and folds used to indicate a certain type of deformation?). Probably the most popular feedback from students was the enjoyment of using Google Earth to provide big-picture interpretations of structure. Second, students were challenged to learn about a new basin or a completely new concept each day. This can take some focus and is akin to the block program featured at some universities in the U.S., including Colorado College. Finally, students enjoyed the fact that each day was a new topic, so that they remained rather fresh and engaged throughout the course.

Some of the key limitations included: (i) exercises were demanding and took significant time, with some students turning in homework after the midnight deadline; (ii) the material was completely new and took focus to learn new lexicons of geologic 
terms required to adequately perform the exercises; and (iii) Internet connectivity issues may have prevented students from hearing the entire lecture live. We addressed these limitations by lowering the workload and setting greater flexibility on deadlines; cutting back on the introduction of new and technical terminology; and recording lectures and putting them and lecture material online the same day.

The 15-day field phase featured modules on rock identification, Laramide orogenyrelated intrusions, and the metamorphic core of the Black Hills. The key observations of this portion of the course included (i) the regular four-day field mapping projects were challenging to scale down to two- to threeday-long mapping projects with the additional health and safety requirements that were needed and in the absence of a day off each week as in the past (five days were previously allowed to grade each project); (ii) more time and lead time is required to do nearly everything in the field camp due to $\mathrm{HS} \& \mathrm{E}$ requirements, leading to longer days for all involved; and (iii) it is more challenging to deliver feedback in the form of grades and constructive criticism when there are no days purely devoted to rest for the students and grading for the instructors.

While four days in the past were adequate to map structures such as the peak near Elkhorn Resort, an asymmetric dome with an underlying intrusion just east of the Wyoming-South Dakota border, the limited time and necessary spacing of cohorts required careful logistical planning. Additionally, flexibility was paramount. Limited time meant that the students might be able to identify rock types and get the structure correct, but for projects in the metamorphic core of the Black Hills, it became exceedingly difficult to recognize multiple Black Hills deformational events in just two days of mapping. Second, the enhanced HS\&E protocols required longer times to do nearly everything because they were accomplished by cohort, from breakfast, to loading the vans, to turning in homework, to distributing field equipment, including Brunton compasses and GPS units. However, one camp event that likely was made logistically easier during this course was the evening virtual meeting to introduce a new project or to review Black Hills geology. Third, the feedback on student projects necessarily needed to be accelerated because there were no rest days in the field portion of the course.
Additional challenges that occurred due to the shorter timeframe in the field included (i) unfamiliarity with measuring fold axes and using a Brunton compass in general; (ii) unfamiliarity with actually measuring a stratigraphic section in the field; (iii) difficulty in providing feedback via the virtual platform or scanned images to students as they worked on their maps and cross sections (i.e., advised not to provide close faceto-face feedback on projects); and (iv) having to schedule "office hours" rather than students having full access to instructors during office days as in a normal BHNSFS camp. These limitations and drawbacks to the online and hybrid approach need to be addressed by the field geoscience education community.

\section{OUTLOOK FOR GEOSCIENCE FIELD-BASED EDUCATION DURING COVID-19 TIMES}

Like with science in general, our fields are never moribund. Based on our field-camp experience this year, many of our peers have asked us to predict what will happen to fieldbased education over the next 5-10 years and in the immediate short term. We feel that while we are unable to make predictions, we can forecast three key scenarios: (i) an increase in hybrid-type field courses with two phases similar to our trial course, which limits the amount of time spent physically in the same location and thereby decreases the risk of an outbreak; (ii) a decrease in field courses as universities accelerate online teaching to accommodate the circumstances of the pandemic and increase global reach; and (iii) an increase in field courses due to an increase in demand from the postponement, delay, and cancellation of courses since early to mid-2020.

The first scenario may become increasingly common in the short term for the following reasons: (i) instructors now have abundant material that they can use to teach remote courses; (ii) the wear-and-tear of travel is significantly reduced for the student and instructor and requires much less logistical preparation; and (iii) this scenario can accommodate both those who learn best online and in the field, so it is more "equal" in its delivery.

The second scenario may occur due to budget cuts, a change in curriculum, or a wholesale acceptance that field camp is no longer required for an undergraduate geoscience degree. We tend to disagree with all of these reasons. For many universities adapting this type of training and course delivery, it bodes well for demand for field courses run by field stations with fairly large year-round enrollments.

Third, we believe demand for field-based courses may actually rise. Of the $\sim 250$ students enrolled to take our field camps for the summer of 2020 , nearly $75 \%$ of them canceled and deferred for a later date. Accounting for the students still in their sophomore and junior years who plan to enroll in field camp during 2021-2022, this could represent a nearly $4 \times$ increase from 2020. This scenario will require advance planning to provide space for all of the students who will enroll in field camp. This rather optimistic scenario also agrees with other observations that "a field camp cannot be run online" and that there is no substitute for "in-the-field mapping" to train students on field geology methods.

\section{CONCLUSIONS}

Due to the COVID-19 pandemic, many field-based geoscience programs have been temporarily suspended. The experiences described herein provide a benchmark for planning and executing hybrid field geology courses during the COVID-19 pandemic. Our aim is to provide these observations as a way to facilitate constructive dialogue among the geoscience education community, including students and faculty and stakeholders alike, to continually hone, refine, and innovate the way we educate our next generation of earth scientists, many of whom will discover important energy resources for our world. We hope this contribution will serve as a useful guide for universities and businesses planning to hold face-to-face activities during this time of uncertainty.

\section{ACKNOWLEDGMENTS}

This study could not have been possible without the support and data provided by the South Dakota School of Mines and Technology and the Black Hills Natural Sciences Field Station. In particular, we thank the late Dr. Alvis Lisenbee for his generosity of spirit in teaching us how to map the challenging terrain of the Black Hills. Dr. Lisenbee spread joy for the geosciences and his enthusiasm for the thrill of discovery in field mapping is a key mindset instilled in all of us. We also thank all of the students and vendors (too numerous to name) involved in creating successful field camps throughout the years. Thank you to D. Chiarella and an anonymous reviewer for their thorough and comprehensive reviews of the manuscript that greatly improved its readability and impact. JR also thanks the brilliant and talented Dr. Pooja Sodha for her inspiration to this contribution. 


\section{REFERENCES CITED}

Anderson, K.S., Hickson, T.A., Crider, J.G., and Graham, S.A., 1999, Integrating teaching with field research in the Wagon Rock project: Journal of Geoscience Education, v. 47, p. 227-235, https://doi.org/10.5408/1089-9995-47.3.227.

Bank, C., and Rotzien, J.R., 2007, Reflections by a Student and a Faculty Member on Student-Faculty Collaborative Geophysical Field Research: American Geophysical Union Fall Meeting, San Francisco, Calif., Supp., abstract no. ED33B-1223.
Chiarella, D., and Vurro, G., 2020, Fieldwork and disability: An overview for an inclusive experience: Geological Magazine, https://doi.org/ $10.1017 / \mathrm{S} 0016756820000928$

Oliveri, S., and Bohacs, K.M., 2005, Field safety in uncontrolled environments: A process-based guidebook: AAPG, Division of Environmental Sciences, ExxonMobil Upstream Geoscience, $150 \mathrm{p}$.

Rotzien, J.R., Sincavage, R., Pellowski, C., Gavillot, Y., Cooper, S., Shannon, J., Sawyer, J.F., Yildiz, U.,
Filkorn, H., and Uzunlar, N., 2020, Field-based geoscience education during the COVID-19 pandemic: Planning and execution, Part II: Geological Society of America, GSA 2020 Connects Online, abstract no. 359659. https://doi.org/10.1130/abs/ 2020AM-359659.

Manuscript ReCeived 4 Sept. 2020

Revised MANUSCRIPT RECEIVED 13 Nov. 2020

Manuscript ACCePted 2 Dec. 2020 